NBER WORKING PAPER SERIES

\title{
A FUNDAMENTAL OBJECTION TO TAX EQUITY NORMS: \\ A CALL FOR UTILITARIANISM
}

Louis Kaplow

Working Paper No. 4961

\section{NATIONAL BUREAU OF ECONOMIC RESEARCH 1050 Massachusetts Avenue \\ Cambridge, MA 02138 \\ December 1994}

I am grateful for comments from Reuven Avi-Yonah, Christine Jolls, Steven Shavell, Joel Slemrod, Al Warren, and workshop participants. This paper is part of NBER's research program in Public Economics. Any opinions expressed are those of the author and not those of the National Bureau of Economic Research.

(C) 1994 by Louis Kaplow. All rights reserved. Short sections of text, not to exceed two paragraphs, may be quoted without explicit permission provided that full credit, including $\odot$ notice, is given to the source. 


\title{
A FUNDAMENTAL OBJECTION TO \\ TAX EQUITY NORMS: \\ A CALL FOR UTILITARIANISM
}

\begin{abstract}
Anti-utilitarian norms often are used in assessing tax systems. Two motivations support this practice. First, many believe utilitarianism to be insufficiently egalitarian. Second, utilitarianism does not give independent weight to other equitable principles, notably concerns that reforms may violate horizontal equity or result in rank reversals in the income distribution. This investigation suggests that a policy maker who believes in the Pareto principle -- that any reform preferred by everyone should be adopted -- cannot consistently adhere to any of these anti-utilitarian sentiments. Moreover, the affirmative case for utilitarian tax policy assessment is stronger than is generally appreciated.
\end{abstract}

Louis Kaplow

Harvard Law School

HFB 322

Harvard University

Cambridge, MA 02138

and NBER 


\section{Introduction}

This article is concerned with the normative principles that should guide tax policy assessment. The simplest and most studied norm is utilitarianism, which favors whatever regime produces the greatest total utility. But most tax policy analysts do not embrace utilitarianism, primarily for two reasons.

First, they find utilitarianism to be insufficiently egalitarian. It is true that utilitarianism favors equality, all things being equal, because of decreasing marginal utility of income: redistributing a dollar from the rich to the poor increases total utility. But complete equalization is rejected because of the adverse effect of redistribution on incentives to work. The objection to utilitarianism is that it gives insufficient weight to equality. The weight it gives is determined by the degree to which individuals' marginal utility declines, which is now understood to be related to risk preferences. But one might favor more equality. ${ }^{1}$ A Rawlsian approach, to take an extreme, would put all weight on the poorest individual (even if most of national wealth were destroyed in the process). ${ }^{2}$ "Moderates" favor intermediate weights. Leading

1 Many have explicitly rejected the connection between individuals' risk preferences and social concerns for equality. See, e.g., Arrow (1951), Rawls (1971), Sen (1973). For an apparent retraction, see Arrow (1973). Rejecting individuals' risk preferences in this context involves paternalism, as indicated in note 16 . Observe that rejection of risk preferences does not necessarily imply a greater preference for equality than that implied by utilitarians rather than less. Absent a contrary derivation from a specific theory of distributive justice, there is no guarantee that an analyst's intuition about distributive weights will entail more of a desire to avoid low incomes than is reflected in various individuals' utility functions. 
articles in the literature on the optimal degree of redistribution -- the optimal income tax literature -- typically report the appropriate tax rates for a range of distributional preferences; utilitarianism is presented as one polar case and the Rawlsian approach as the other. ${ }^{3}$ Aside from utilitarians and followers of Rawls, however, few have attempted to offer a moral theory to justify the degree of egalitarian preference; the choice is left to intuition. No consensus or leading view has emerged.

second, utilitarianism is viewed as deficient for ignoring equitable concerns about the relative positions of individuals in the income distribution. Horizontal equity -- the command that equals be treated equally -- has received the greatest attention. A possibly related concern for avoiding reversals in individuals' positions in the income distribution is often expressed. A substantial literature develops equity indexes designed to measure violations of these norms, and such measures have been used to assess various tax reforms." There has been virtually no attempt to ground such approaches in a theory of distributive justice.5 Although many believe there are norms worthy of

2 It is common to refer to this approach as "Rawlsian" due to Rawls' advocacy of this position, although the actual implementation of his egalitarian norm in tax policy and social choice theory often departs from his particular presentation.

3 See, e.g., Atkinson (1970), Mirrlees (1971), Stern (1976). Atkinson (1973) suggests broader extreme boundaries, as when there is an anti-Paretian preference for greater equality.

4 See, e.g., Aronson and Lambert (1994), Atkinson (1980), Feldstein (1976), King (1983), Musgrave (1990), Plotnick (1981).

5 Most articles are entirely silent on this question. Indexes are stipulated, with features defended or criticized using ad hoc appeals to intuition. For a critique, see Kaplow (1989). Musgrave (1990) seeks to defend horizontal equity by indicating how it is not affronted by various 
independent weight in evaluating tax reforms, there is substantial variation in proposed measures and little consensus on even basic premises.

Section 2 of this article demonstrates that both criticisms of utilitarianism are fundamentally misguided, as least for policy makers who accept the Pareto principle. The Pareto principle holds that a regime preferred by all individuals should be implemented. The principle is appealing because it involves a rather limited value judgment that most find acceptable, at least in the context of rather sterile comparisons of tax reforms in which the only data presented are individuals' after-tax incomes in various regimes. The principle, however, is rarely invoked in assessing tax policy because, on its face, it is inapplicable to real tax reforms. When there are millions of tax units, it is inconceivable that any reform, no matter how wonderful, would literally improve everyone's lot. Moreover, tax policy often is concerned with the appropriate distribution of income, which is not a question the Pareto principle purports to address.6

Nonetheless, the Pareto principle has important implications for tax policy norms. In particular, section 2 presents examples in which adherence to any of the anti-utilitarian tax equity norms leads the policy maker to reject reforms that are preferred

theories of distributive justice in a simple, first-best world, even though it is violated in a more complicated world. The index he offers, however, does not purport to derive from any of the distributive theories he discusses.

6 The Pareto principle does imply that the policy maker should not be more egalitarian than Rawls' extreme position. Similarly, it implies a limit on the weight that may be given various equity norms: it would conflict with a horizontal equity norm of such weight that two "equals" would be given an income of 50 rather than allowing one to get 60 and the other 70 . 
by all individuals. In other words, no one who believes in the Pareto principle can consistently accept any of the views on tax equity that are prominent in the literature.

There are two respects in which this utilitarian endorsement should not be surprising. First, there is a sense in which the utilitarian claim is obvious. The Pareto principle, after all, commands that social decisions must respect individuals' preferences. All of the anti-utilitarian equity norms give weight to factors that are not of concern to individuals, so it is inevitable that adherence to such norms can lead to a conflict with the Pareto principle.

Second, work in decision theory and social choice theory established essentially the same conclusion long ago.' Among the first and most important demonstrations are offered by Harsanyi $(1953,1955,1977) .{ }^{8}$ One of his arguments involves a proof that any rational, consistent social decision maker who cared about individuals' preferences would have to be a utilitarian. This work has not, however, penetrated discussions of tax policy, perhaps because of its technical nature and because the intuition for the results and their application to tax equity norms is not immediately apparent. For this reason, section 3 briefly surveys

7 In the tax policy literature, Stiglitz (1982) established the possible inconsistency between a concern for horizontal equity and the Pareto principle. But this aspect of his article did not provoke much reaction, perhaps because the article (including the title) emphasized the conflict of horizontal equity with utilitarianism rather than with the Pareto principle and because most of the article uses complex analysis to establish subtle points about the optimality of randomization in taxation.

8 The present article's examples and some of the discussion are close in spirit to Harsanyi's original work as well as other work in decision theory and social choice theory, particularly Fleming (1952), Hildreth (1953), Maskin (1978), Myerson (1981), Ng (1981), Strotz (1958), and Vickrey $(1945,1960)$. 
two derivations of utilitarianism from ethically appealing assumptions. Section 4 addresses some of the issues that have proved controversial in these literatures to see whether they qualify the suggestion that utilitarianism is the appropriate norm for tax policy.

2. Demonstration that Tax Equity Norms Are in Fundanental Conflict with the Pareto Principle

The question addressed. -- It is useful to be as precise as possible at the outset about what the examples to follow are designed to demonstrate. The question is whether one can consistently adhere to both an anti-utilitarian tax equity norm and the Pareto principle. The motivation rests on the assumption that those who believe in these norms purport to believe in them consistently. Thus, for example, if one's equity index registered -10 in considering one reform, the same index would be applied in assessing a similar reform, rather than stipulating the index to be zero if it just so happened that the latter reform involved a particular individual having income equal to some unlucky number or resulted in a violation of the Pareto principle.

Second, I assume that these anti-utilitarian norms are intended to have independent significance; that is, I assume they are not mere tie-breakers. ${ }^{9}$ Another way to state the point is that, for whatever norm one has in mind, one would be willing to pay something, some positive amount, to avoid the violation of

9 Because a perfect tie is quite unlikely, tie-breaking norms are hardly important, and I doubt the literature on these other norms is intended to serve only this trivial purpose. 
the norm. Thus, one would prefer an alternative regime that differed in only two respects: (1) the norm violation was eliminated or materially reduced, and (2) each individual had a little less income. The amount by which income is less can be small: a dollar, a cent, or a millionth of a cent. The point is simply that the norm has no independent significance if we should not be willing to pay even a tiny fraction of a cent to avoid violating it.

Example: egalitarianism and horizontal equity. -- Consider a reform that moves from regime I to regime II:

$\begin{array}{ccc}\text { REGIME I } & & \text { REGIME II } \\ 50,50 & \Rightarrow & 60,40\end{array}$

The numbers indicate income levels of two individuals, each of whom has the same utility function, where utility is simply a function of income. In regime $I$, two individuals each have income of 50. In regime II, they have incomes of 60 and 40; which individual has which income is determined by chance, where there is a fifty percent probability of each outcome.

If one has a preference for equality, regime I is better because there is less inequality, under any conceivable measure. In addition, equal treatment of equals is not provided in the move to regime II. Thus, if one gives independent significance to either of these anti-utilitarian norms, regime I is superior to regime II. (Another example, below, will address reversals in positions in the income distribution.) 
I now wish to modify the example slightly, to make the choice of regimes more of a real contest. Consider the following:

$$
\begin{array}{cc}
\text { REGIME I } & \text { REGIME II } \\
50-c, 50-c \quad \Rightarrow \quad 60,40
\end{array}
$$

Here, each individual's income is lower by $C$ in regime I (the status quo). For example, it might be that regime II is more arbitrary because it forgoes the added expense entailed by more precise rules or higher quality audits and adjudication.

Which regime is now preferable? If either of the antiutilitarian norms has independent significance, regime I is still strictly better than regime II if $C$ is not too large (for example, if it is a tiny fraction of a cent). One can view $c$ as the cost of achieving equity and ask whether incurring the cost is justified by the norm in question. As previously explored, it is assumed that one is willing to pay something to avoid inequity.

Demonstration of conflict with the Pareto principle. -Suppose first that individuals are risk neutral. That is, individuals are indifferent between receiving, say, 100 of income for certain and taking a gamble that may result in higher or lower income, but has an expected value of 100 (perhaps a double or nothing bet turning on the toss of a coin).

When individuals are risk neutral, it is obvious that the anti-utilitarian norms conflict with the Pareto principle. Each individual has an expected income of 50 if regime II is implemented (recall that income is 60 or 40 , each outcome having 
a fifty percent chance). Under regime $I$, income is only 50 - $C$.

All individuals, therefore, strictly prefer regime II and would prefer to move to regime II no matter how low the level of $c$ that must be paid, as long as $\mathrm{C}$ is not literally zero. Yet adherence to either of the anti-utilitarian norms requires selecting regime I if $c$ is not too high. By contrast, a utilitarian would adopt regime II, because the sum of utilities (in this example, reflected simply by the sum of incomes) is greatest in that regime. The conclusion is that utilitarianism is consistent with the Pareto principle but each of the anti-utilitarian norms conflicts with the Pareto principle.

One might object that the assumption of risk neutrality is unrealistic and indeed removes a source of motivation for preferring regime $I$. But any equitable norm that is truly appropriate should be used consistently and should not depend on what individuals' preferences happen to be. Thus, the failure of the anti-utilitarian norms in this simple case should be decisive if one accepts the Pareto principle.

Nonetheless, it is instructive to consider the case in which individuals are risk averse. Suppose further that no insurance is available, so individuals would actually bear the risk in moving to regime II. ${ }^{10}$ In this case, individuals would be willing to pay something to avoid the move to regime II because

\footnotetext{
10 If there was imperfect insurance (for example, if only partial insurance were available or if there were a loading charge), one could modify slightly the argument in the text to produce the same result. If there was perfect insurance, the analysis would be like that when individuals are risk neutral (except that the result might be deemed irrelevant because the actual incomes in regime II would not be 60 and 40 , but instead would be 50 and 50 after insurance payments were taken into account).
} 
the move entails risk. Let $\mathbf{R}$ denote the most that individuals would be willing to pay to avoid imposition of this risk. This amount is commonly referred to as a risk premium. It reflects the maximum amount an individual would pay for complete insurance. In this example, insurance is unavailable if there is to be a move to regime II. But insurance is implicitly available because it is feasible to stay in regime $I$. staying in regime $I$, however, entails a cost of $C$. If $C<R--$ that is, if the cost of implicit insurance were less than the risk premium -individuals would unanimously prefer regime $I$. If $C>R$, individuals would unanimously prefer regime II. (If $C=R$, each individual would be indifferent.)

Now consider application of the equity norms. A pure utilitarian would make precisely the same choices as individuals. In evaluating the added inequality of income in regime II, a utilitarian would use individuals' utility functions. The utilitarian is averse to inequality by exactly the extent to which individuals are averse to risk. Thus, as when individuals were assumed to be risk neutral, utilitarianism is consistent with the Pareto principle.

For the anti-utilitarian norms, the conclusion is different. To be of any relevance, such norms must give some weight to regime I. Moreover, they must give more weight than utilitarianism. (If they give exactly the same weight, they are not independent norms; rather, they are merely convoluted restatements of utilitarianism. Those who advance these norms are expressly anti-utilitarian; that is the whole point.) 
Suppose this additional weight is 24 per capita. ${ }^{11}$ Consider the case in which $C$ is 14 greater than the risk premium: $C=R+1$. Then, both individuals strictly prefer to move to regime II: the cost of avoiding the risk by staying in regime I exceeds the value of avoiding the risk. But the equity norm would require the policy maker to choose regime I. After all, regime I costs only 14 per capita more than what a utilitarian would deem it to be worth, but the policy maker believes that the equity norm, which is respected in regime $I$ but violated in regime II, is worth 24 per capita. Therefore, regime I would be chosen, despite individuals' unanimous preferences to the contrary.

Example: rank reversals. To incorporate rank reversals, consider the following modified example:

$\begin{array}{clc}\text { REGIME I } & & \text { REGIME II } \\ 50,50 & \Rightarrow & 60,40 \\ 40,40 & \Rightarrow & 50,30\end{array}$

This example simply combines two instances of the prior example: the initial pair of individuals with income of 50 and another pair with income of 40 , where each individual under the reform again has a fifty-fifty chance of having income rise or fall by 10. Observe that, by combining these pairs of individuals, the move from regime I to regime II now involves a pure reversal in positions between the "rich" person who ends up with income of 40 and the "poor" person who ends up with income of 50. Thus, giving any weight to avoiding rank reversals entails a strict preference for staying in regime $I$ : that is, the regime would be

11 It will be obvious that any amount, say, 2 millionths of a cent, will do for the argument. 
chosen even if there were some added cost to each individual in regime I, as long as that cost is not too high.

Because this example is simply the combination of two instances of the initial example, it is obvious that one can analyze this case in the same manner as the preceding one. There will exist circumstances -- levels of the added cost of staying in regime I -- in which any anti-utilitarian norm (such as a norm of avoiding rank reversals) that entails a preference for regime I will sometimes choose regime I when all individuals would prefer the reform of moving to regime II. ${ }^{12}$ The norm of avoiding rank reversals, therefore, also conflicts with the Pareto principle.

Summary. -- The examples just presented may have a trivial air: equity norms valued in cents, individuals' choices decided by a penny. The argument, however, invokes logical consistency, and the demonstration uses small amounts to drive home the point. Even one who believes that greater equality, avoiding horizontal equity, or preventing reversals in the income distribution is worth a mere $2 \zeta$ per capita may find himself making choices that are unanimously opposed, that violate the Pareto principle.

It is no answer to this inconsistency that actual examples involving violation of the Pareto principle would not arise in practice. If they did, the consistent policy maker who believed

\footnotetext{
12 The only complication is that one must decide how to allocate the cost $\mathrm{C}$ between the "rich" and "poor" in regime $I$. When individuals are risk averse, it suffices to set $C_{r i c h} / C_{\text {poor }}$ equal to $R_{\text {rich }} / R_{\text {poor }}$. Thus, if $C_{\text {rich }}<R_{\text {rich }}$ (which, given how the cost ratio is set, implies $C_{\text {poor }}<R_{\text {poor }}$ ), individuals would unanimously prefer regime I. If instead the costs exceeds the risk premiums, individuals would unanimously prefer regime II.
} 
in any of the anti-utilitarian norms would have to trump individuals' unanimous preferences. This suggests that, at the foundational level, these principles all conflict with the Pareto principle.

I also note that, although the example is contrived, it involves no sleight of hand. The structure is simple. The character of the conflict is realistic: spending less on administration and the like often produces more arbitrariness in results. Real decisions in designing tax systems present such choices. To be sure, there usually would not be strict unanimous preference; all it takes is one person who loses a minute when reading new instructions, only to learn that he is unaffected by the reform. But if evaluative norms are to be applied consistently, it hardly will do to advocate qualitatively different principles depending on whether or not such a person exists.

\section{The Affirmative Case for Utilitarianism}

Although only a simple example, the preceding demonstration suggests that tax policy makers should be utilitarians if they hold individual welfare in sufficient regard that unanimous preference for a regime should not be trumped. It is useful to supplement this argument with two more systematic affirmative arguments for utilitarianism that have been developed by Harsanyi and others. ${ }^{13}$ Moreover, there is a close connection between

\footnotetext{
13 The seminal papers are Harsanyi (1953, 1955); a useful restatement appears in Harsanyi (1977). Some important precursors and subsequent work are cited in note 8 .
} 
these arguments and the analysis in the preceding example.

The veil of ignorance. -- Although the veil of ignorance has come to be associated with Rawls' (1971) argument that we should maximize the well-being of the worst-off individual, the construct was earlier used by Harsanyi (1953) and Vickrey (1945), who argued that a utilitarian approach follows. Their reasoning is straightforward. A normatively appealing way to conceptualize disinterested social choice is to assume that individuals do not know their actual position in society. In particular, each person behind the veil of ignorance is just as likely to be one person (say, the richest person) as another (the poorest person). If the total population is $N$, a person behind the veil reasons: I have a $1 / \mathrm{N}$ chance of being each person $i$, whose utility in regime $X$ is $U_{1}(X)$; the best $I$ can do for myself is maximize my expected utility, which is $\frac{1}{N_{i}} \sum_{1}^{N} U_{i}(X)$. Thus, individuals behind the veil would choose the regime that maximizes the sum (average) of individuals' utilities.

The individual's situation is logically equivalent to one in which he knows his identity, has actual control over a decision, and knows that there are $N$ equally likely outcomes that have associated utilities $U_{1}(X)$. Von Neumann and Morgenstern (among others) have rigorously demonstrated that minimal assumptions of rationality imply the maximization of expected utility. If individuals in the original position are rational, therefore, it must be that they would be utilitarians, Rawls' contrary assertions notwithstanding. ${ }^{14}$ Note that even individuals in the 
world who know their circumstances would tend to favor some utilitarian element in policy making. After all, many individuals (particularly the young) face significant uncertainty about their future well-being, and those concerned about their descendants will have an even greater concern for the average well-being of members of society.

Rational social choice. -- Harsanyi (1955) offered a second derivation of utilitarianism. This approach makes three sets of assumptions. (1) Individuals are rational utility-maximizers. (This is a descriptive rather than a normative assumption.)

Social choice also should be rational, namely: alternatives should be completely and consistently (transitively) ordered; social welfare should rise if outcomes improve; welfare should be continuous in probabilities (e.g., a policy with a slightly higher chance than another of a better outcome should be slightly preferred). (3) Social choice should appropriately reflect individuals' preferences: if all individuals are indifferent between two regimes the choice should socially be one of

\footnotetext{
14 Rawls (1971) and followers who accept the veil construct reject the utilitarian conclusion, usually for one of the following reasons: (1) Those in the original position do not know that the probabilities of being each person are $1 / N$, and they may not be. But why not set the probabilities this way and tell everyone in the original position? Any other probabilities would imply favoritism for some individuals over others. Also, as long as the probabilities of all persons in the original position becoming each actual person sum to one, which they must, reference can be made to a "pre-original position" in which individuals each have a $1 / \mathrm{N}$ probability of being any person in the original position; then utilitarianism would follow by Harsanyi's (1953) original argument. This can hardly be objectionable, because individuals behind the veil are supposed to unanimously agree. (2) Infinite risk aversion is assumed. But the logic of the situation requires using the actual utility functions of individuals in society, which already entail particular risk preferences that are not plausibly infinite. (3) Rawls would use "primary goods" rather than utility. But this has no logical nexus to maximizing the position of the worst-off individual. Indeed, the approach is like imputing an identical utility function to each individual, in which case utilitarianism would follow.
} 
indifference; social welfare should raise rather than fall with individual welfare; each individual should receive equal weight.

Under these assumptions, Harsanyi proved that social choices must conform to the dictates of utilitarianism: the unique social welfare function maximizes the sum of individuals' utilities. The normative appeal has two elements, corresponding to the second and third sets of assumptions: social choices should be rational, and they should even-handedly reflect individuals' preferences. (The latter requirement is approximately the same as assuming that social choices are consistent with the Pareto principle.) Although not immediately apparent, and perhaps even counter-intuitive, a utilitarian prescription necessarily follows.

Given this derivation, section 2's demonstration that all the anti-utilitarian tax policy norms conflict with the Pareto principle is not surprising. Harsanyi rigorously showed that respect for individuals' well-being of the sort embodied in the Pareto principle, combined with logical consistency of social decisions, implies utilitarianism. The method of Harsanyi's proof exploits properties of consistency when decisions involve uncertainty. My examples similarly involve uncertainty, which often exists in the realm of tax policy. Moreover, as will be explored in section 4 , the examples could be seen as involving uncertainty in a different sense: there may be no uncertainty regarding the effects of a reform, but only concerning the identities of winners and losers. Disinterested social policy requires that social choices not depend on these identities. 
(Decisions may depend on whether, for example, a particular loser is rich or poor, but not on which rich person or which poor person is the loser.) This, in turn, is similar to a veil of ignorance construct, in which utilitarianism is also implied.

\section{Discussion}

Section 2 indicates that anti-utilitarian tax equity norms are in fundamental conflict with a respect for unanimous individual preferences (the Pareto principle), and section 3 presents two affirmative derivations of utilitarianism from ethically appealing assumptions. Nonetheless, a range of considerations and objections need to be examined; even most committed utilitarians admit qualifications of some sort. A brief article on tax equity norms cannot be the place for a comprehensive analysis or defense. It is appropriate, however, to consider some of the issues.

My claim in this section is that many objections to the Pareto principle or utilitarianism, if persuasive, are either inapplicable in the present context or call for adjustments. Most importantly, such arguments do not support the sorts of anti-utilitarian principles that are criticized in this article. I believe, therefore, to have made a prima facie case against these departures from utilitarianism. Adherents to conflicting tax equity norms need to present some affirmative justification for their views and for particular indexes designed to implement them. Indeed, it is unclear how one can proceed intelligently with measurement or with giving weight to such norms without 
knowing more precisely what they are or why we think they

exist. ${ }^{15}$

Critigues of the Pareto principle. -- The present argument depends upon accepting the Pareto principle, so the primary way to avoid the utilitarian conclusion is to reject the principle. One criticism of the Pareto principle is that it takes individuals' preferences as given. Individuals may be misinformed (they may misjudge the probability of an event), their judgment may be questioned at a deeper level (paternalism), or some preferences (envy, racism) may simply be rejected as morally irrelevant. But accepting these criticisms does not seriously affect the present argument. One could substitute "corrected" preferences for actual preferences.16 Thus, the policy maker could consider individuals" "true" utility rather than perceived utility or could ignore utility arising from impermissible preferences. Then, the Pareto principle applied to these adjusted preferences would conflict with each antiutilitarian norm but would be consistent with utilitarianism applied to the adjusted preferences. Note, moreover, that none

\footnotetext{
15 Related, indexes of inequality, such as the Gini coefficient, are unfounded if they cannot be shown to measure adherence to some normative principle and if any norm to which they might be relevant must be rejected because of its confilct with the Pareto principle. In addition, such generic measures of inequality are unnecessary if an explicit social welfare function, such as a utilitarian one, has been specified. See Atkinson (1970).

16 See, e.g. Harsanyi (1955, 1977). Hammond (1987) argues that one can incorporate greater egalitarianism by imposing different risk preferences on individuals (a view some have argued to be implicit in Rawls' approach). As he clearly indicates, this paternalistic approach conflicts with the Pareto principle as generaliy understood. It entalls, for example, that individuals would be forced to buy insurance that they properly understood as too expensive (given their correct views on the risks involved) or forbidden to pursue risky entrepreneurship (even when they accurately assess the consequences). Hammond does not suggest why such overriding of preferences is morally required.
} 
of these criticisms about individuals' preferences provides a justification for any of the anti-utilitarian norms. In the tax policy context, these norms have simply been applied to levels of after-tax income; there is no connection between the norms and indexes, on one hand, and any misunderstanding of tax reforms or improper expenditure of income, on the other hand.

Another possibility is that individuals might have direct preferences for the distributional characteristics reflected in anti-utilitarian norms: for example, they may want incomes to be equal. Theoretically, this is wholly consistent with the Pareto principle and utilitarianism: individuals' utilities would reflect these aspects of the income distribution and the correct procedure would be to sum the utilities thus defined. One would not engage in axiomatic derivations of equity indexes or ponder characteristics of the just society in the manner of a moral philosopher. Rather, this question is empirical, so one would conduct opinion polls or engage in other research about the preferences of typical citizens. ${ }^{17}$ Those advancing anti-

17 To illustrate, Boskin and Sheshinski (1978) show that if individuals' utility depends substantially on their relative income, a utilitarian optimal income tax will be much more redistributive than otherwise. They argue, however, that policy should not be based on their results unless there is an empirical demonstration that individuals actually have such preferences. A possible response is that the moral philosophers deem a norm to be correct based upon their reflection and intuition; therefore, the "true" best interest of all individuals, if they are to be moral persons, is to have such a preference. And, because we believe in paternalism, we should impute this personal preference for our asserted norm, so the correct "utilitarian" position is to take the norm into account in making social decisions. Although one could argue this, some affirmative justification for the norm seems necessary, and the problem of avoiding criticism through circular argument that is described in the text to follow is present. Interestingly, one could generate the sort of anti-utilitarian norms discussed here -greater egalitarianism, avoiding unequal treatment and reversals in position -- if one assumed that individuals were very envious, but envy is precisely the sort of preference that many are inclined to ignore even when individuals actually have such feelings. 
utilitarian tax equity norms have not claimed that the particular concerns for equity and distribution, as captured in various proposed measures, have a real correspondence to individuals' actual preferences. ${ }^{18}$

In addition, whatever individuals' preferences about such equitable norms might be, there is some question as to whether they should be given weight in the described manner. It has been suggested that individuals should be viewed as having two sets of preferences: personal preferences about their own well-being (and others to whom they feel attachments) and moral preferences about what society should be like. ${ }^{10}$ If they are morally worthy citizens, they would vote for policy based on the latter preferences. But when an individual asks why she should hold a particular social preference, one might expect the reasons to be concerned with effects on individuals. To incorporate social judgments into personal preferences confuses the issue. Moreover, it results in circularity. If an equity norm is initially held by all, but is in error, how could it ever be criticized? If all hold it, all favor it; therefore, society should act on it. The present article is designed to show that the anti-utilitarian norms, which have not been independently justified, are probably mistaken because in principle they can

\footnotetext{
18 For example, individuals who receive promotions do not share their pay raises with peers to whom they feel similarly situated. To be sure, some aspects of the income distribution may affect individuals' preferences. For example, Gurr (1970) argues that "relative deprivation" is an important cause of social unrest and revolution. But the empirical claims he makes concern the relationship between groups' well-being and their expectations, which may be influenced by gains of relevant reference groups, rather than the bare fact of unequal income.
}

19 See, e.g., Harsanyi (1955, 1975). 
require choosing regimes that are to the detriment of everyone. If most individuals make this same mistake, they might indeed vote for such regimes, and one could then argue that the result is not truly to everyone's detriment. But on reflection, I suggest, if the only appeal of the norm is that it matches current belief, it qualifies as a personal preference (which a utilitarian may or may not wish to respect) but not as an independent ethical norm.

other questions about the Pareto principle have been raised. ${ }^{20}$ The main point to note is that objections are almost invariably of two types. First, there are objections to basing social decisions on individual welfare. But the anti-utilitarian tax policy norms are generally based directly on individual welfare. Second, one may question whether social welfare is always affected positively by individual welfare. For example, a distribution in which both the rich and the poor have incomes of 10 might be deemed preferable to one in which the rich have 50 and the poor 40. If one accepts such a view, the appropriate

20 The claim most discussed in social choice theory is Sen's (1970) "Paradox of a Paretian Liberal." I am unconvinced for reasons related to those given in Blau (1975), Farrell (1976), Gibbard (1974), and $\mathrm{Ng}$ (1971). Essentially, Sen postulates (1) that there are some matters, which books each individual reads, on which each individual's preferences should be socially decisive, no matter what, and (2) an example in which each individual cares more about what others read than about what he reads, and wishes policy to reflect this. Thus, his "liberals" (actually, "libertarians") all hold anti-liberal preferences, hardly a persuasive setting in which to make libertarianism paramount. Relatedly, he ignores that the liberal notion of entitlements usually contemplates that entitlements may be voluntarily transferred. (The extreme example is labor: imposed slavery is prohibited, but individuals may sell labor.) Sen's (1976) defense suggests that he is paternalistic or believes that anti-libertarian preferences (e.g., regarding what others read) should be ignored. Alternatively, one might find his example appealing on rule-utilitarian grounds: we believe individuals usually do care mostly about their own reading, and we distrust a public censor who purports to be implementing citizens' wishes to the contrary. Each of these arguments are considered in the text. 
anti-utilitarian norm would be rather different from, and more striking than, the principles of tax equity that have been advanced in the literature.

Other criticisms of utilitarianism. -- The Pareto principle is not sufficient to derive utilitarianism. For example, selfish dictatorship (choose the policy that is in Joe's best interests, without regard to the welfare of everyone else) is consistent with the Pareto principle: no policy preferred by the dictator would ever be trumped. Section 3 explored the additional assumptions used in derivations of utilitarianism, namely that social choices be rational and give equal weight to each individual.

Utilitarianism entails, however, an additional premise (one shared with the anti-utilitarian equitable norms): interpersonal comparisons of utility are assumed to be meaningful. ${ }^{21}$ Despite the emphasis on ordinalism in welfare economics during the middle of the twentieth century, it is now generally accepted that interpersonal comparisons of utility are necessary if distributional judgments are to be made. ${ }^{22}$ For example, a statement that a rich person has greater well-being than a poor person, at least on average, involves a comparison of utility

\footnotetext{
21 Greater egalitarianism is made concrete by putting weight on disparities in welfare levels, which must then be assessed. Who is equal in the status quo or how one ranks for purposes of measuring reversals also requires such assessments. See, e.g., Feldstein (1976). Particularly when taxpaying units vary - e.g., married versus single, number of dependents - - one must undertake some direct comparison of utility for distributive judgments to be possible. Also, utility rather than income must be considered if one is to provide meaningful measures for violations of equity. (E.g., does inequality matter more, less, or the same amount among the rich? Is twice the inequality in treatment just as bad, twice as bad, or ten times worse?)

22 See, e.g., Harsanyi (1955, 1975, 1977), Sen (1979).
} 
levels. Suggesting that a dollar is generally worth more to the poor than to the rich involves comparing marginal contributions to utility. A number of writers have addressed this subject, and it is not in any event pertinent to the choice among norms addressed here. ${ }^{23}$

There is also the question of which income distributions count when applying tax equity norms. ${ }^{24}$ For example, regime II can be described in terms of final incomes (in the table) or in terms of the actual risks to which each individual is exposed (in the verbal description, in which each individual in the first example has a fifty-fifty chance of an income of 60 or 40 ). To a utilitarian, these descriptions are equivalent. But different descriptions may lead to different social judgments for antiutilitarians. For example, risk-neutral individuals are indifferent between 50 for sure and a fifty-fifty chance of 60 or 40, and the utilitarian criterion assesses both worlds equally. But each of the anti-utilitarian judgments finds the final result -- one person with 60 and the other with 40 -- to be inferior to that in which each has 50. But if regime II is described as giving each individual the same type of lottery ticket, some anti-utilitarians might argue that no inequity is involved by

\footnotetext{
23 It has often been suggested that utilitarianism imposes greater demands than a Rawlsian approach because it requires comparisons of units of utility rather than merely utility levels. See, e.g., Arrow (1973). But this view is largely mistaken, because cardinality of individual utility (implied by rational choice under uncertainty) and interpersonal comparability of utility levels together imply sufficient comparability of utility units for utilitarianism. See $\mathrm{Ng}$ (1984). (The converse is not true: the comparability of units required for utilitarianism does not entail the comparability of levels required for Rawlsian and other non-utilitarian approaches.)

24 Diamond's (1967) influential criticism can be interpreted as raising this question. See the related discussions in Broome (1984), Deschamps and Gevers (1979), Harsanyi (1975), Myerson (1981), $\mathrm{Ng}$ (1981), Strotz (1958).
} 
moving to regime II. This, in turn, would salvage their position as consistent with the Pareto principle.

There are serious problems with this defense. First, as the equity norms have been presented in the literature, measured by indexes, and applied in evaluating actual tax reforms, this is not the approach taken. Second, in the actual contexts in which these norms are advocated -- general tax reforms that have a range of difficult to predict effects -- the lottery description is indeed accurate. And even when particular winners and losers can be identified in advance upon investigation, they are hardly known to the policy maker who is relying upon results from largescale simulations that use an anonymous data base. Thus, the information available to the social decision maker is precisely that described in the examples.

Indeed, one could characterize reforms as involving two steps: (1) the reform is analyzed using aggregate data, (2) a further investigation is done to determine the personal identities of the winners and losers. Implicitly, the argument is that a wholly different normative evaluation must be performed at step 2 than at step 1. Alternatively, step 1 could be deemed the proper point of evaluation, which would salvage consistency with the Pareto principle but eliminate the practical bite of horizontal equity and rank reversal norms. There remains the claim that the ex ante income distribution should be more egalitarian than a utilitarian would require. This raises a final problem: the arbitrariness of the status quo, which was produced by a series of prior reforms spanning years, decades, 
even centuries. ${ }^{25}$ If the ex ante view is adopted, should one not go all the way back, to an "original position" before individuals know anything about what will transpire in the world? As section 3 notes, from that position utilitarianism would immediately follow.

A rather different critique of utilitarianism involves taking a libertarian approach, under which regimes are not evaluated by any sort of welfare function but rather with regard to whether designated entitlements are respected. Any distributive effect that infringed upon entitlements might be decisive against a reform. It is not clear that any modern tax system would be legitimate under this view, unless one invokes ex ante social contract reasoning. If the social contract is entered after individuals' know their abilities to earn income, they would not unanimously consent to much redistribution and it is likely that there would be at least one vote against virtually any regime. If the social contract is imagined to be entered behind a "veil of ignorance," however, utilitarianism would be the unanimous choice, so there would be no conflict. Finally, it should be noted that none of the anti-utilitarian tax equity norms in the

\footnotetext{
25 The problem of identifying which regime is entitled to special status is extremely important for concerns about horizontal equity and rank reversals. For example, if regime II in the second example is the status quo, the move to regime I is Inequitable due to rank reversals and involves no violation of horizontal equity (there are no ex ante equals - - although if the individuals with incomes of 40 and 50 in regime II instead both has incomes of 45 , returning to regime I would violate horizontal equity). Thus, the routine practice of applying such equity indexes to the status quo to analyze a pending reform seems virtually impossible to defend, particularly when many reforms involve the repeal of recent enactments. The status quo is also essential for egalitarians, as any nonlinear function of individual utilities can be shown to yleld prescriptions that are dynamically inconsistent -. that is, which depend upon the point in the policy-making sequence at which the evaluation is undertaken. See, e.g., Hammond (1983).
} 
literature are implied by libertarianism. Libertarians are not concerned with unequal treatment or rank reversals per se; they object to any reduction in welfare that violates entitlements. In particular, a reform that moved all individuals' incomes closer to the mean, with perfect equal treatment and no rank reversals, is just the policy usually offered to illustrate what libertarians find most objectionable about taxation. But such a reform satisfies all the anti-utilitarian tax equity norms considered here.

Institutional considerations. -- Many commentators have objected that utilitarianism is insufficiently concerned about the process by which a particular distribution of income might be generated. ${ }^{26}$ Such concerns no doubt motivate the attention devoted to horizontal inequity and rank reversals. Inequity may be arbitrary, arise from improper action (perhaps discrimination against minorities or political opponents), or reflect a denial of equal opportunity.

These concerns should be taken seriously, but are not directly pertinent to tax equity norms of the sort proposed in the literature. Consider the unequal treatment or change in positions in the income distribution that arises in the tax reforms that have been analyzed. Virtually all such inequity is produced in one of two ways. First, there is simply the

26 Diamond (1967) uses the language of "process," as do others, but the actual process concern is unstated. Indeed, in the contexts examined, the only process differences involved may be whether a result having a given probability arises from a single or two-stage lottery, a matter unlikely to be of independent normative significance (although many authors imply that it is). For a discussion of some of the issues considered here, see stiglitz (1982). 
randomness described above, which is inevitable when uncertainty is ubiquitous and perfect administration is costly if not impossible. ${ }^{27}$ Second, inequity may arise when particular provisions are intentionally changed, but then the change may be evaluated directly. For example, raising the personal exemption for the blind will treat unequally individuals with the same income but who differ with respect to eyesight. As a matter of equity, one might favor or oppose such a change, but a horizontal equity index would be superfluous because it begs the question whether eyesight is relevant to the social allocation of resources. Alternatively, raising the personal exemption for everyone would treat unequally families with the same income but different numbers of dependents. But to invoke horizontal equity to oppose such a change assumes that different-sized families are equals in the normatively relevant sense, which begs the question about the proper treatment of dependents. Those favoring the change would argue that only with the higher exemption is "equal treatment" provided. ${ }^{28}$

\footnotetext{
27 Attention to unequal treatment of equals may be relevant in this context for the purposes of identifying how much inequality actually exists. The reason is that, as a matter of convenience, analysts often compare pre- and post-reform (after-tax) incomes for individuals in, say, each decile of the income distribution. But if there is unequal treatment of equals, the amount of inequality within deciles will not be constant. See Atkinson (1980). It also need not be constant even if there is equal treatment within deciles. For precise measures of overall equality, one simply needs micro-data rather than decile averages, but once such data is available there is no need for a separate horizontal equity index.

28 In principle, utilitarianism is capable of addressing these issues. The most difficult question for utilitarianism (and most other distributive principles) is the treatment of children, to the extent fertility is responsive to tax policy. (An increase in the population might raise total utility but reduce average utility, and there is much disagreement about which criterion is most compeliing.)
} 
By contrast to such instances of possible inequity, some tax policies raise real process concerns. For example, a method of audit may give too much opportunity for abuse by government officials, or a tax court might be biased against racial minorities. It is wholly consistent with utilitarianism -particularly rule utilitarianism -- that systems should be designed with a concern for minimizing such problems. ${ }^{29}$

The anti-utilitarian tax equity norms do not address this issue directly. Nonetheless, paying attention to horizontal equity and rank reversals might sometimes be useful in this context because the observation of a violation can motivate investigations into the cause of "inequity," which might occasionally turn out to involve improper behavior that can then be corrected. The equity index is thus used as a warning signal, just as a doctor might consider an otherwise benign physical symptom in deciding whether to perform a diagnostic procedure. Such use of an equity index, however, is qualitatively different from using the index to measure the weight to be given to an independent norm in assessing policy, particularly in a context like tax reform in which the index will routinely indicate violations that are innocuous.

\section{Conclusion}

In assessing tax policy, there is disagreement about how egalitarian the income distribution should be in light of the

\footnotetext{
29 Related, individuals' perceptions of inequitable government action -- even when not reflecting reality - - may be a source of concern, as by breeding disrespect for the law. Rule utilitarians would account for this phenomenon.
} 
incentive problems that arise with redistributive taxation. Additional ethical concerns have been raised -- notably, that horizontal inequity and reversals in individuals' positions in the income distribution should be avoided. Usually, the norms and indexes are merely stipulated or are supported by ad hoc appeals to intuition.

The central argument presented here is that all tax equity norms that depart from utilitarianism are inconsistent with adherence to the Pareto principle, a belief that reforms preferred by everyone should be adopted. Most tax policy analysts believe in the Pareto principle. Moreover, there exist ethically appealing derivations of utilitarianism. Although objections and qualifications have long been noted, it appears that none undermine the present arguments or provide a justification for the anti-utilitarian principles and indexes developed in the literature. As a result, the case against these other tax equity norms and in favor of utilitarianism is strong. At a minimum, it is hard to justify continued adherence to the anti-utilitarian norms until a serious effort is made to defend them more directly and to explain why the Pareto principle should not merely be qualified, but wholeheartedly rejected. 
Aronson, J. Richard and Peter J. Lambert. "Decomposing the Gini Coefficient to Reveal the Vertical, Horizontal, and Reranking Effects of Income Taxation." National Tax Journal 47 (1994): 273-294.

Arrow, Kenneth J. Social Choice and Individual Values. 1st ed. New York: Wiley, 1951.

Arrow, Kenneth J. "Some Ordinalist-Utilitarian Notes on Rawls's Theory of Justice." Journal of Philosophy 70 (1973): 245-263.

Atkinson, Anthony B. "On the Measurement of Inequality." Journal of Economic Theory 2 (1970): 244-263.

Atkinson, Anthony B. "How Progressive Should the Income Tax Be?" In M. Parkin, ed. Essays in Modern Economics. London: Longmans, 1973.

Atkinson, Anthony B. "Horizontal Equity and the Distribution of the Tax Burden." In Henry Aaron and Michael J. Boskin, eds. The Economics of Taxation. Washington: Brookings Institution, 1980 .

Blau, J.H. "Liberal Values and Independence." Review of Economic studies 42 (1975): 395-402.

Boskin, Michael J. and Eytan Sheshinski. "Optimal Redistributive Taxation When Individual Welfare Depends upon Relative Income." Quarterly Journal of Economics 93 (1978): 589-601.

Broome, John. "Uncertainty and Fairness." Economic Journal 94 $(1984)$ : 624-632.

Deschamps, Robert and Louis Gevers. "Separability, Risk-Bearing and Social Welfare Judgments." In Aggregation and Revelation of Preferences. Jean-Jacques Laffont, ed. Amsterdam: NorthHolland, 1979 .

Diamond, Peter A. "Cardinal Welfare, Individualistic Ethics, and Interpersonal Comparison of Utility: Comment." Journal of Political Economy 75 (1967): 765-766.

Farrell, M.J. "Liberalism in the Theory of Social Choice." Review of Economic Studies 43 (1976): 3-10.

Feldstein, Martin. "On the Theory of Tax Reform." Journal of Public Economics 6 (1976): 77-104.

Fleming, Marcus. "A Cardinal Concept of Welfare." Quarterly Journal of Economics 66 (1952): 366-384.

Gibbard, Alan. "A Pareto-Consistent Libertarian Claim." Journal of Economic Theory 7 (1974): 388-410.

Gurr, Ted R. Why Men Rebel. Princeton: Princeton University Press, 1970 .

Hammond, Peter. "Ex-post Optimality as a Dynamically consistent objective for collective Choice Under Uncertainty." In Social Choice and Welfare. P.K. Pattanaik and M. Salles, eds. Amsterdam: North-Holland, 1983.

Hammond, Peter J. "On Reconciling Arrow's Theory of Social Choice with Harsanyi's Fundamental Utilitarianism." In Arrow and the Foundations of the Theory of Economic Policy. George R. Feiwel, ed. London: Macmillan Press, 1987. 
Harsanyi, John C. "Cardinal Utility in Welfare Economics and in the Theory of Risk-Taking." Journal of Political Economy 61 (1953): 434-435.

Harsanyi, John C. "Cardinal Welfare, Individualistic Ethics, and Interpersonal Comparisons of Utility." Journal of Political Economy 63 (1955): 309-321.

Harsanyi, John C. "Nonlinear Social Welfare Functions: Do Welfare Economists Have a Special Exemption from Bayesian Rationality?" Theory and Decision 6 (1975): 311-332.

Harsanyi, John C. Rational Behavior and Bargaining Equilibrium in Games and Social Situations. Cambridge: Cambridge University Press, 1977.

Hildreth, clifford. "Alternative Conditions for Social Orderings." Econometrica 21 (1953): 81-94.

Kaplow, Louis. "Horizontal Equity: Measures in Search of a Principle." National Tax Journal 42 (1989): 139-154.

King, M.A. "An Index of Inequality: with Applications to Horizontal Equity and Social Mobility." Econometrica 51 (1983): 99-115.

Maskin, Eric. "A Theorem on Utilitarianism." Review of Economic Studies 45 (1978): 93-96.

Mirrlees, J.A. "An Exploration in the Theory of Optimum Income Taxation." Review of Economic Studies 38 (1971): 175-208.

Musgrave, Richard A. "Horizontal Equity, Once More." National Tax Journal 43 (1990), 113-122.

Myerson, Roger B. "Utilitarianism, Egalitarianism, and the Timing Effect in Social Choice Problems." Econometrica 49 $(1981)$ : 883-897.

Ng, Yew-Kwang. "The Possibility of a Paretian Liberal: Impossibility Theorems and Cardinal Utility." Journal of Political Economy 79 (1971): 1397-1402.

$\mathrm{Ng}$, Yew-Kwang. "Bentham or Nash? On the Acceptable Form of Social Welfare Functions." Economic Record 57 (1981): 238-250.

$\mathrm{Ng}$, Yew-Kwang. "Interpersonal Level Comparability Implies Comparability of Utility Differences." Theory and Decision 17 (1984): 141-147.

Plotnick, Robert. "A Measure of Horizontal Inequity." Review of Economics and statistics 63 (1981): 283-288.

Rawls, John. A Theory of Justice. Cambridge: Harvard University Press, 1971 .

Sen, Amartya K. "The Impossibility of a Paretian Liberal." Journal of Political Economy 78 (1970): 152-157.

Sen, Amartya K. On Economic Inequality. Oxford: Clarendon Press, 1973 .

Sen, Amartya K. "Liberty, Unanimity and Rights." Economica 43 (1976): 217-245.

Sen, Amartya K. "Interpersonal Comparisons of Welfare." In Economics of Human Welfare: Essays in Honor of Tibor Scitovsky. Michael J. Boskin, ed. New York: Academic Press, 1979.

Stern, N.H. "On the Specification of Models of Optimum Income Taxation." Journal of Public Economics 6 (1976): 123-162.

stiglitz, Joseph. "Utilitarianism and Horizontal Equity: The Case for Random Taxation." Journal of Public Economics 18 $(1982): 1-33$. 
Strotz, Robert H. "How Income Ought to Be Distributed: A Paradox in Distributive Ethics." Journal of Political Economy 66 (1958): 189-205.

Vickrey, william. "Measuring Marginal Utility by Reactions to Risk." Econometrica 13 (1945): 319-333.

Vickrey, william. "Utility, strategy, and social Decision Rules." Quarterly Journal of Economics 74 (1960): 507-535. 